\title{
Microbial community diversity patterns are related to physical and chemical differences among temperate lakes near Beaver Island, MI
}

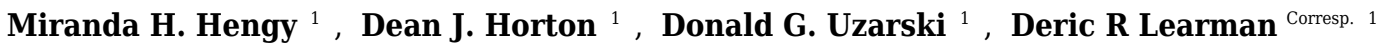 \\ 1 Institute for Great Lakes Research and Department of Biology, Central Michigan University \\ Corresponding Author: Deric R Learman \\ Email address: deric.learman@cmich.edu
}

Lakes are dynamic and complex ecosystems that can be influenced by physical, chemical, and biological processes. Additionally, individual lakes are often chemically and physically distinct, even within the same geographic region. Here we show that differences in physicochemical conditions among freshwater lakes located on (and around) the same island, as well as within the water column of each lake, are significantly related to aquatic microbial community diversity. Water samples were collected over time from the surface and bottom-water within four freshwater lakes located around Beaver Island, MI within the Laurentian Great Lakes region. Three of the sampled lakes experienced seasonal lake mixing events, impacting either $\mathrm{O}_{2}, \mathrm{pH}$, temperature, or a combination of the three. Microbial community alpha and beta diversity was assessed and individual microbial taxa were identified via high-throughput sequencing of the 16S rRNA gene. Results demonstrated that physical and chemical variability (temperature, dissolved oxygen, and $\mathrm{pH}$ ) were significantly related to divergence in the beta diversity of surface and bottomwater microbial communities. Despite its correlation to microbial community structure in unconstrained analyses, constrained analyses demonstrated that dissolved organic carbon (DOC) concentration was not strongly related to microbial community structure among or within lakes. Additionally, several taxa were correlated (either positively or negatively) to environmental variables, which could be related to aerobic and anaerobic metabolisms. This study highlights the measurable relationships between environmental conditions and microbial communities within freshwater temperate lakes around the same island. 
1 Microbial community diversity patterns are related to physical and chemical differences among 2 temperate lakes near Beaver Island, MI

3

4 Miranda H. Hengy, Dean J. Horton, Donald G. Uzarski, and Deric R. Learman*

5

6 Institute for Great Lakes Research and Department of Biology, Central Michigan University, Mt.

7 Pleasant, MI, 48859, U.S.A.

8

9 *Corresponding author: Deric R. Learman, Mailing address: Department of Biology, 3111 10 Biosciences Building, Central Michigan University, Mt. Pleasant, MI, 48859. Email address:

11 deric.learman@cmich.edu

12

13

14

15

16

17

18

19

20

21

22

23 


\section{ABSTRACT}

25 Lakes are dynamic and complex ecosystems that can be influenced by physical, chemical,

26 and biological processes. Additionally, individual lakes are often chemically and physically

27 distinct, even within the same geographic region. Here we show that differences in

28 physicochemical conditions among freshwater lakes located on (and around) the same island, as

29 well as within the water column of each lake, are significantly related to aquatic microbial

30

31

32

34 community diversity. Water samples were collected over time from the surface and bottom-water within four freshwater lakes located around Beaver Island, MI within the Laurentian Great Lakes region. Three of the sampled lakes experienced seasonal lake mixing events, impacting either $\mathrm{O}_{2}$, $\mathrm{pH}$, temperature, or a combination of the three. Microbial community alpha and beta diversity were assessed and individual microbial taxa were identified via high-throughput sequencing of the 16S rRNA gene. Results demonstrated that physical and chemical variability (temperature, dissolved oxygen, and $\mathrm{pH}$ ) were significantly related to divergence in the beta diversity of surface and bottom-water microbial communities. Despite its correlation to microbial community structure in unconstrained analyses, constrained analyses demonstrated that dissolved organic carbon (DOC) concentration was not strongly related to microbial community structure among or within lakes. Additionally, several taxa were correlated (either positively or negatively) to environmental variables, which could be related to aerobic and anaerobic metabolisms. This study highlights the measurable relationships between environmental conditions and microbial communities within freshwater temperate lakes around the same island. 
46

47

48

49

50

51

52

53

54

55

56

57

\section{INTRODUCTION}

Lakes are complex ecosystems that span a range of physical and chemical properties, which are driven by differences in formation, hydrology, weather patterns, and geology (Wetzel, 2001). Further, even lakes within the same geographic region can vary widely in physicochemical conditions, both spatially and temporally based on formation, age, and trophic status (Clement et al., 2015). The physical and chemical attributes of a lake can impact microbial communities and the biogeochemical processes they mediate, since microbial communities are governed by local environmental conditions. The essential processes regulated by microbial communities include, but are not limited to, nutrient cycling (e.g. carbon, nitrogen, and sulfur), which supports biologically suitable environmental conditions within lakes (Essington \& Carpenter 2000), as well as chemical export, such as respiration of $\mathrm{CO}_{2}$, and other redoxsensitive elements (Paerl \& Pinckney 1996; Pilcher et al. 2015). As microbial community function is related to microbial community composition (Bier et al. 2015), and community composition is constrained by local environmental conditions, it is important to explore microbial communities within individual lakes.

1 While environmental conditions are unique to each lake, environmental gradients can also occur within some lakes that physicochemically stratify. Water column mixing, or turnover, followed by a return to stratified conditions is a natural ecosystem disturbance that occurs seasonally in many lakes. This phenomenon is known to influence microbial communities, as a consequence of shifting environmental conditions, and even impacts microbial community assembly mechanisms (Tammert et al. 2005; Shade et al. 2008; Shade et al. 2010a; Shade et al. 2010b; Shade et al. 2011; Shade et al. 2012b; Garcia et al. 2013; Meuser et al. 2013; Andrei et al. 2015). The stratification of water masses at different temperatures and densities results in a 
69 hypolimnion that is not only colder, but tends to have lower dissolved oxygen and $\mathrm{pH}$ relative to

70 the epilimnion as the rate of decomposition tends to exceed photosynthesis (Fenchel \& Finlay

71 2008). Furthermore, inorganic nutrients (e.g., C, N, and P) may accumulate in the hypolimnion

72 (Tõnno et al. 2005; Zadereev et al. 2014). Lake mixing events can transport dissolved organic

73 carbon (DOC; described as the amount of $\mathrm{C}$ within a system) throughout lakes (Mostofa et al.

74 2005; Kim et al. 2006; Li et al. 2008), and dissolved organic matter (DOM; quality of organic

75 matter as described in Chappaz et al. (2013)) has previously been shown to vary between upper

76 and lower layers of lakes (Mostofa et al. 2005). This suggests that structurally different organic

77 compounds may not only differ among lakes, but also characterize each layer in some lakes. In

78 addition, both DOC and DOM have been found to shape microbial community composition

79 depending upon carbon source and concentration (Cotner \& Bidanda 2002; Burkert et al. 2003;

80 Crump et al. 2003; Eiler et al. 2003; Grossart et al. 2008; Amaral et al. 2016; Lucas et al. 2016).

81 As previously stated, chemical and physical components are major drivers of bacterial

82 community structure and population shifts, therefore, lake stratification can present a major

83 disturbance for bacterial communities and may impact microbial communities structure as lakes

84 gradually stratify post-mixing.

85

Research to date demonstrates that microbial communities respond to disturbance with

86 various degrees of resistance and resilience, depending upon the existing community and 87 qualities of the disturbance (Allison \& Martiny 2008; Shade et al. 2011). For example, microbial 88 communities may show resistance to lake mixing and physicochemical stratification, remaining 89 unaffected in the face of disturbance (Shade et al. 2012a). However, depending upon the 90 physicochemical attributes disturbed (e.g., $\mathrm{O}_{2}$, nutrients, $\mathrm{pH}$, specific conductance etc.), 91 disturbance influences microbial communities differentially in extent of community change, 
92 resistance, and resilience (Shade et al. 2011). Additionally, different subsets of microbes within a

93 community (e.g., generalist vs rare taxa) can experience different patterns of resistance and

94 resilience. Illustrating this, Shade et al. (2010b) found that many generalist taxa are resistant to

95 mixing and subsequent changes of temperature and dissolved oxygen levels. Nevertheless,

96 individual taxa (often specialist or rare) can be positively or negatively influenced as a result of

97 physicochemical shifts and show fundamentally different reactions to mixing than dominant

98 community members (Shade et al. 2010a; Shade et al. 2010b). As such, microbial communities

99 can vary between lakes due to differences in lake chemistry, as well as within lakes at finer

100 scales for the same reason.

101 In this study, three freshwater inland lakes of Beaver Island, Michigan, USA, as well as

102 an adjacent location within Lake Michigan, were sampled to evaluate the relationship between

103 microbial communities and local physicochemistry within surface-water and bottom-water

104 habitats (epilimnion and hypolimnion during stratification). These lakes were selected as they

105 each hosted unique and contrasting physicochemical properties (Clement et al., 2015). Two of

106 the lakes were holomictic and experienced oxygen stratification, while another holomictic lake

107 (Lake Michigan) did not experience stratification at the point of sampling, but did experience a

108 thermocline. The final lake (Barney's Lake) is a shallow lake which did not experience a mixing

109 event and lacked physicochemically stratified layers. Specifically, we sought to explore the

110 relationships between microbial community diversity and environmental variables known to

111 stratify within lakes. We also explored microbial community diversity change over time within

112 each lake with respect to post-mixing stratification of environmental variables or a lack thereof.

113 Physical and chemical parameters were collected in conjunction with high resolution microbial 
114 community data (via 16S rRNA gene sequencing) to explore relationships between microbial

115 taxa and natural physicochemical gradients among and within sampled lake systems.

116

\section{METHODS}

\section{Sampling locations}

Three inland lakes on Beaver Island, MI (Fox Lake [FL], Barney's Lake [BL], and Lake

120 Geneserath [LG], located on Beaver Island, MI) and Lake Michigan (St. James Harbor [LM];

121 Fig. 1) were sampled during three collection periods in the summer of 2014: period 1 (June 10-

122 11), period 2 (July 28-30), and period 3 (Aug. 30-31). Sampling sites for the three inland lakes

123 were located at the region of greatest depth (at $3.6 \mathrm{~m}$ for Barney's Lake, $15.2 \mathrm{~m}$ for Lake

124 Geneserath, and 6.1 m for Fox Lake). Lake Michigan bottom sampling depth ranged from 14.5-

$12518.3 \mathrm{~m}$, depending upon small-scale spatial bathymetric differences. While Lake Michigan was

126 not sampled at the point of greatest depth (as were other lakes in this study), we attempted to 127 sample Lake Michigan to a similar depth as inland lakes within this study.

128 Surface and bottom-water samples were collected using a Kemmerer (Wildco®) water

129 sampler. During each collection period, samples were retrieved from surface (one meter below

130 the surface) and bottom-water (one meter above the lake sediment) locations for each site. For 131 each sample, water was collected in an acid washed sterile bottle. From this bottle, $90 \mathrm{ml}$ of 132 water was filtered through a $0.45 \mu \mathrm{m}$ filter (Whatman) into acidified vials (resulting $\mathrm{pH}$ of 3 ) and 133 stored on ice for DOC analysis. For collection of microbial samples, $120 \mathrm{ml}$ of water was syringe 134 filtered through a combination of two filters $(2.2 \mu \mathrm{m}$ first, followed by and $0.22 \mu \mathrm{m}$ filters $)$. The 135 filters were flash frozen (dry-ice and ethanol bath) in the field, and then stored at $-80{ }^{\circ} \mathrm{C}$. Once 136 per sampling period, $120 \mathrm{ml}$ of sterilized Nanopure water was filtered and frozen in the field as a 
137 control for microbial samples. The remaining water was stored on ice and then filtered $(0.45 \mu \mathrm{m})$

138 in the lab for nutrient analyses.

139

A calibrated Hydrolab ${ }^{\circledR}$ DS5 (OTT Hydromet, Germany) was used to generate a

140 physicochemical profile of each lake prior to sample collection. Measured parameters included

141 dissolved oxygen (percent and $\mathrm{mg} / \mathrm{L}$ ), temperature $\left({ }^{\circ} \mathrm{C}\right.$ ), and $\mathrm{pH}$ (raw data can be found in

142 Supplementary Table 1).

143

\section{Water Chemistry Analyses}

145 For nutrient analysis, $250 \mathrm{ml}$ of water from each sampling location and depth was filtered

146 in the lab through a $0.45 \mu \mathrm{m}$ filter (Whatman) and frozen at $-20{ }^{\circ} \mathrm{C}$. A Quaatro Bran+Luebbe

147 Auto Analyzer with an XY-2 Sampler (Seal Analytical, Mequon, WI) was used to determine

148 soluble reactive phosphorus (SRP), ammonium $\left(\mathrm{NH}_{4}\right)$, nitrate $\left(\mathrm{NO}_{3}{ }^{-}\right)$, total nitrogen (TN), and

149 total phosphorus (TP) concentrations in the water. An additional $10 \mathrm{ml}$ of water was filtered

$150(0.45 \mu \mathrm{m})$ and acidified for dissolved organic matter (DOM) analysis. Proxies of DOM were

151 characterized by their specific absorption coefficient (SAC340) (Chappaz et al. 2013; Curtis \&

152 Adams 1995) and specific UV absorbance (SUVA254) (McKnight et al. 2001; Weishaar et al.

153 2003). Triplicates of each sample were placed into quartz cuvettes $(1 \mathrm{~cm}$ width $)$ and UV

154 absorbance readings were taken at two different wavelengths: $254 \mathrm{~nm}$ and $340 \mathrm{~nm}$. Samples

155 collected for DOC analysis (described above) were quantified using a Shimadzu TOC-V

156 analyzer (Kyoto, Japan). Raw water chemistry data can be found in Supplementary Table 2.

157

158 Microbial Taxonomic Analysis 
160 (following the manufacturer's protocol). DNA was extracted from both .22 and $2.2 \mu \mathrm{m}$ filters

161 from the same sample simultaneously. All samples were concentrated in a Zymo DNA Clean \&

162 Concentrator $^{\mathrm{TM}}$ kit before being quantified by a Qubit ${ }^{\circledR} 2.0$ Fluorometer (Life Technologies).

163 Control samples yielded DNA that was below detection limits $(<0.5 \mathrm{ng} / \mathrm{mL})$. In order to obtain a

164 sufficient amount of DNA for downstream sequencing, PCRs were completed for each sample to 165 amplify the 16S rRNA gene using high-fidelity Taq polymerase (New England BioLabs Inc., 166 Ipswich, MA) and 27F and 1492R primers (Weisburg et al. 1991). PCR conditions implemented 167 were as follows: initial denaturation at $95^{\circ} \mathrm{C}$ for $5 \mathrm{~min}$., followed by $36-40$ cycles (denaturation 168 at $95^{\circ} \mathrm{C}$ for $30 \mathrm{sec}$, annealing at $56^{\circ} \mathrm{C}$ for $30 \mathrm{sec}$, and extension at $72^{\circ} \mathrm{C}$ ), and final extension at $16972^{\circ} \mathrm{C}$ for $10 \mathrm{~min}$. Number of cycles for each sample varied due to differences in amplification 170 (Supplementary Table 3), which was visualized through gel electrophoresis. Replicate PCRs for 171 each sample were pooled. PCR samples were purified using the QIAquick ${ }^{\circledR}$ Gel Extraction Kit 172 (Qiagen). Three sampling points were excluded from microbial community data analysis, which 173 included bottom-water time point " 1 " for Lake Michigan and both surface and bottom-water 174 community profiles for Fox Lake time point "3". These samples were excluded, as they either 175 did not contain sufficient concentration or quality of DNA for sequencing or analysis. V4 16S 176 rRNA amplicons were generated using previously described methods and primers $16 \mathrm{Sf}-\mathrm{V} 4$ 177 (515f) and 16Sr-V4 (806r) (Kozich et al., 2013) and sequenced on an Illumina MiSeq platform 178 using a paired end 2 x 250 bp format (accomplished by Michigan State University’s Research 179 Technology Support Facility).

Sequence data were processed using MOTHUR v.1.35.1 (Schloss et al. 2009). Quality 181 control and clustering steps were implemented following the publicly available MiSeq SOP 
182 (found at www.mothur.org/) with modifications. Briefly, sequences which were less than $251 \mathrm{bp}$

183 or greater than $254 \mathrm{bp}$ in length were removed from further analyses, as were sequences which

184 contained $>8$ homopolymers. Sequences were aligned using the SILVA (v. 119) reference

185 database (Quast et al. 2012). Sequences which were not aligned within the V4 region were also

186 removed. UCHIME (Edgar et al. 2001) was used to check for chimeric DNA, which was

187 subsequently removed. Sequences were classified using the RDP database (training set v9; Cole

188 et al. 2013). Classifications corresponding to chloroplast, eukaryotic, or mitochondrial DNA, as

189 well as sequences that classified as unknown, were removed. The remaining data were clustered

190 into operational taxonomic units (OTUs) using a 0.03 dissimilarity threshold. The Mothur

191 workflow associated with this study can be found within an online repository located on GitHub

192 (https://github.com/horto2dj/CMUBS_microb). Sequences obtained for this study have been

193 deposited in the MG-RAST database (Meyer et al. 2008) under accession numbers

194 mgm4732740.3 - mgm4732751.3, mgm4732757.3, mgm4732760.3, mgm4733677.3 -

195 mgm4733686.3, mgm4733688.3, mgm4733690.3 - mgm4733704.3, and mgm4733784.3 -

196 mgm4733785.3. Additional metadata associated with submitted environmental sequences can be

197 found within Supplementary Table 3.

198

199 Statistical Analyses

200 Statistical analyses (both chemical and biological) were completed using the R statistical

201 software v.3.2.1 (R Core Team, 2015). Protocols and files associated with quality control and

202 statistical tests can be found on GitHub (https://github.com/horto2dj/CMUBS_microb).

203 Differences in lake chemistry among lakes and time points within lakes were analyzed through

204 principal component analysis (PCA). 

samples were normalized using the DeSeq2 package (Love et al. 2014) in R, followed by a variance stabilizing transformation (McMurdie \& Holmes 2014). as random effect) and ANOVA were used to test significance of habitat (i.e., surface vs bottomwater) on levels of alpha diversity. Linear models and ANOVA were used to test for differences in alpha diversity between lakes. Alpha diversity values were correlated with measured

213 environmental variables using Spearman's rank correlation to explore relationships between 214 environmental variables and alpha diversity.

215 Non-metric multidimensional scaling (NMDS) based on Bray-Curtis distance was 216 performed to compare dissimilarity between the samples, also employing the PhyloSeq package. 217 A total of 20 iterations were accomplished to reach the lowest stress during NMDS and two 218 dimensions $(\mathrm{k}=2)$ were used for visualization. Analysis of Similarity (ANOSIM) was used to 219 test for significant differences in community composition between microbial communities of 220 different lakes. Correlation of environmental variables with microbial communities was 221 determined using envfit of the Vegan package (Oksanen et al. 2007). Canonical Correspondence 222 Analysis (CCA) was implemented to explore relationships between environmental variables 223 significantly correlated to beta diversity in NMDS and microbial community beta diversity. 224 Permutation tests were implemented to test significance of axes and environmental variables 225 within CCA in explaining microbial community beta diversity patterns using 999 permutations in 226 all tests. Partial Canonical Correspondence Analysis (pCCA) was implemented to specifically 
227 examine potential effects of oxygen gradients on microbial communities in the same way as 228 described above.

229 Spearman's Rank correlations were used to identify OTUs significantly correlated to 230 environmental variables (i.e., dissolved oxygen, $\mathrm{pH}$, and temperature). Only OTUs which 231 appeared within a minimum of 5 samples with at least 2 sequences were considered for 232 correlation analyses. Variance stabilizing transformation was used to normalize sequence 233 abundances across samples for these OTUs to account for uneven sequencing depth between 234 samples. Correlations with $\mathrm{p}>0.001$ and $\mathrm{r}<0.65$ were excluded as an attempt to reduce 235 spurious correlations. OTUs which could not be identified as belonging to a phylum were 236 removed from analyses.

237

RESULTS \& DISCUSSION

239

240

241

242

243

244 245 246 247 lakes.

248 249

\section{Physicochemical variation among and within lakes}

Fundamental differences in lake physicochemistry were observed between Lake Michigan and inland lakes on Beaver Island (Fig. 2; Table 1). Lake Michigan water chemistry was distinguished based upon DOC, $\mathrm{NO}_{3}{ }^{-}$, and SAC340 concentrations, showing considerable divergence from the remaining three lakes (Fig. 2). Lake surface physicochemistry (temperature, DOC concentrations, and DOM properties) was nearly indistinguishable between Barney's Lake and Lake Geneserath. Fox Lake surface water chemistry was also similar to that of Barney's Lake and Lake Geneserath, but was slightly dissimilar due to a lower $\mathrm{pH}$ with respect to other

Of the lakes sampled, Lake Geneserath and Fox Lake experienced oxygen, temperature, and $\mathrm{pH}$ stratification over time between surface and bottom-waters (Fig. 2, Supplementary Table 
250 2). The bottom-water in both lakes experienced lower temperatures, elevated acidity, and lower

251 oxygen levels with respect to the surface-water. DOC concentrations and DOM quality did not

252 vary significantly (two-tailed t-test, $\mathrm{p}>0.05$ ) between surface-water and bottom-water

253 environments for any lake. Barney's Lake and Lake Michigan did not experience

254 physicochemical stratification at the points sampled. However, Lake Michigan bottom water

255 experienced decreased temperatures, but did not plateau with increasing depth, suggesting that 256 the thermocline rather than the hypolimnion was developed at the sampling location.

257

258 Microbial community taxonomy and alpha diversity among lakes

259

A total of 3,415,100 sequences were obtained across all samples prior to filtering and

260 quality control steps. After quality filtering steps, 2,058,143 sequences remained and from these

261 sequences 51,831 OTUs were identified. Sequencing depth ranged from 54,802 to 136,518 total

262 sequences among samples. After singletons and doubletons were removed, a total of 20,372

263 OTUs remained for diversity analyses. There were no significant differences in alpha diversity

264 among lakes according to linear models and ANOVA. However, linear mixed-effect models and

265 ANOVA found that habitat type (i.e., surface vs bottom-water) significantly influenced Shannon

266 diversity levels $(\mathrm{p}<0.01$ ), with higher levels of diversity occurring in bottom-water habitat

267 versus the surface-water (Table 2). Previous literature that suggests anoxic hypolimnion

268 communities are more diverse (alpha diversity) than their respective epilimnion (Humayoun et

269 al. 2003; Shade et al. 2012b; Meyerhof et al. 2016), which is consistent with our findings in lakes

270 which developed anoxic hypolimnia (Fox Lake and Lake Geneserath). Two of the lakes within

271 this study, Barney's Lake and Lake Michigan, did not develop anoxic hypolimnia, yet these

272 systems experienced higher alpha diversity in their bottom-water environments with respect to 
273 surface waters. These differences in alpha diversity (namely evenness) between surface and

274 bottom-water environments may be driven by other variables, such as temperature (in Lake

275 Michigan), or other variables not measured in this study, such as light penetration. A separate

276 study exploring microbial communities along a Lake Michigan transect south of our sampling

277 location did not find differences in alpha diversity between epilimnion and hypolimnion

278 environments (Fujimoto et al. 2016). However, as we did not sample the hypolimnion of Lake

279 Michigan in our study, our results are not directly comparable to the findings of Fujimoto et al.

280 (2016). Despite this, we found differences between Lake Michigan epilimnion and thermocline

281 environments, which suggests potentially higher diversity within the thermocline with respect to

282 the surface water environment.

283 Taxonomically, members of Proteobacteria, primarily Betaproteobacteria, were

284 generally the most dominant taxa (based on relative abundance) found within the sequenced

285 microbial community in all the explored lakes (Fig. 3). Other dominant phyla (>1\% community

286 composition) within the lake systems included Acidobacteria, Actinobacteria, Armatimonadetes,

287 Bacteroidetes, Firmicutes, Gammatimonadetes, Planctomycetes, and Verrucomicrobia. These

288 phyla have frequently been shown to dominate freshwater communities (Attermeyer et al. 2015;

289 Boucher et al. 2006; Taipale et al. 2009; Zwart et al. 2002). The most abundant OTU within the

290 inland lakes, and second most abundant in Lake Michigan, was related to Polynucleobacter

291 within Betaproteobacteria. This microbial genus has been commonly found in freshwater

292 systems, with levels up to $60 \%$ community composition found in one freshwater pond (Hahn

293 2003; Hahn et al. 2005; Hahn et al. 2010; Jezbera et al. 2011) and represented the third most

294 dominant OTU of another stratified lake (Garcia et al. 2013).

295 


\section{Environmental relationships with microbial beta diversity}

297 Beta diversity ordinations incorporating all sites showed microbial communities

298 separated based on the sampling location (or lake) (Fig. 4; ANOSIM $R=0.789, p=0.001$ ).

299 Significant relationships $(\mathrm{p}<0.001)$ were found between environmental conditions and

300 microbial beta diversity, including correlations between community structure and dissolved

301 oxygen $(r=0.645)$, dissolved organic carbon $(r=0.790), \mathrm{pH}(\mathrm{r}=0.593)$, and temperature $(\mathrm{r}=$

302 0.699). Environmental variables found to significantly correlate to beta diversity in NMDS (i.e.,

303 DO, DOC, $\mathrm{pH}$, and temperature) were tested as constraining variables on beta diversity. CCA

304 was found to be significant $(\mathrm{F}=1.4245, \mathrm{p}<0.001)$ in explaining microbial beta diversity among

305 all samples (Supplemental Fig. 1). Constraining variables explained $26.26 \%$ of variation in CCA.

306 CCA1 and CCA2 were both significant $(\mathrm{p}<0.001)$, explaining $31.28 \%$ and $28.56 \%$ of

307 constrained variation, respectively. $\mathrm{DO}$ and $\mathrm{pH}$ were significant constraints on microbial

308 community beta diversity $(\mathrm{p}<0.001)$, as was temperature to a lesser degree $(\mathrm{p}<0.05)$. DOC,

309 however, was not found to be significantly related to microbial community beta diversity.

310 Similarly, Jones et al. (2009) found that DOC concentration does not predict microbial

311 community structural differences, but rather quality of organic carbon (as measured by water

312 color : chlorophyll-a) is significantly related to microbial community structure in freshwater

313 lakes. The influence of DO on microbial community structure is of particular interest due to

314 oxygen's influence on regulation of redox cycles within aquatic systems. As such, partial CCA

315 (pCCA) examining the strength of dissolved oxygen as an environmental constraint on microbial

316 community structure was accomplished while controlling for temperature and $\mathrm{pH}$ within sampled

317 lakes. Partial CCA found that oxygen alone was significantly related to microbial community

318 composition ( $\mathrm{p}<0.001$, Supplemental Fig. 2) irrespective of the influence of $\mathrm{pH}$ and 
319 temperature. The lakes sampled within our study were all located on (or near) Beaver Island

320 within $17 \mathrm{~km}$ of each other, yet they were physicochemically diverse, suggesting that

321 environmental constraints on microbial communities are stronger than geographic distance.

322 These results are consistent with established theory that microbial community structure and taxa

323 can be highly constrained by environmental factors within lakes, while geographic proximity of

324 lakes may explain to a lesser degree microbial community structure (Yannarell \& Triplett 2005;

325 Van der Gucht et al. 2007).

326 Surface and bottom-water microbial communities within lakes that experienced oxygen

327 and pH stratification (Lake Geneserath and Fox Lake) separated over time (Fig. 4). These results

328 are consistent with previous research that has found divergence of microbial community beta

329 diversity between epilimnia and hypolimnia after lake mixing events (Shade et al. 2010a),

330 particularly in relation to differences in oxygen as a strong constraint (Shade et al. 2008; Shade

331 et al. 2011). Interestingly, while surface-water microbial communities remained relatively stable

332 within these stratifying lakes, bottom-water communities showed marked divergence over time.

333 Previous studies have illustrated that hypolimnetic communities are not resistant to disturbances,

334 particularly disturbances related to oxygen or key nutrient shifts (Allison \& Martiny 2008; Shade

335 et al. 2011; Shade et al. 2012b). Our results corroborate that lake stratification may be an

336 important factor in shaping these communities across freshwater lakes which experience water

337 column mixing events. Contrastingly, within lakes which did not experience stratification,

338 community composition was indistinguishable between surface-water and bottom-water

339 communities within each lake respectively. Previous research has found that microbial

340 communities within oxygenated hypolimnia of Lake Michigan and other deep lakes are often

341 structurally distinct from the respective epilimnia (Fujimoto et al. 2016; Okazaki et al. 2017). It 
342 is likely that we did not find distinctness between surface water and bottom water communities

343 of Lake Michigan, as the hypolimnion of Lake Michigan was not sampled within this study. The

344 Lake Michigan sampling point was also shallower in depth than locations explored by Okazaki et

345 al. (2017) and a separate location than studied by Fujimoto et al. (2016).

346

347 Taxonomic relationships to environmental variables

928 microbial OTUs were found within a minimum of 5 samples and these shared OTUs

were analyzed for correlations with measured environmental variables. In general, specific

350

taxonomic groups (at the level of genus or higher) appeared to be either positively or negatively

351

correlated to levels of dissolved oxygen, as there was little contrast in correlation direction from

352

the same taxonomic group (Fig. 5a). Specifically, members of the phylum Bacteroidetes were

353 primarily positively correlated with dissolved oxygen $(\mathrm{n}=6)$, where only one Bacteroidetes

354 OTU was negatively related to dissolved oxygen. Within Bacteroidetes, a representative OTU

355 from the genus Algoriphagus, which has been described as a strict aerobe (Bowman et al. 2003;

356 Liu et al. 2009), was found to positively correlate with dissolved oxygen concentrations.

357 Members of Flavobacteria have been known to be primarily aerobic (Bernardet et al. 1996), and

358 were also found to positively correlate to dissolved oxygen concentration. Other OTUs, related

359 to Sphingobacteriales (including Chitinophagaceae), contain representative aerobic microbial

360 taxa (Rosenberg 2014) and are common in freshwater bodies within the Great Lakes basin (Mou

361 et al. 2013), so it is not surprising to find these taxa within aerobic freshwater environments

362 within the temperate freshwater lakes of the Great Lakes region. Comamonadaceae were

363 generally positively related with dissolved oxygen levels, however, one representative was

364 negatively correlated. Research has demonstrated that some members of this primarily aerobic 
365 family indeed can grow under anaerobic conditions (Ramana \& Sasikala 2009). Many OTUs

366 related to the order Burkholderiales also increased with oxygen availability. It is likely that these

367 taxa are unable to adapt to developing anoxia within the hypolimnion of chemically stratifying

368 lakes, and may play more dominant roles within the epilimnion after stratification has occurred 369 post-mixing.

370 To the contrary, several individual OTUs negatively correlated with dissolved oxygen.

371 Members of the phyla Acidobacteria, Actinobacteria, Alphaproteobacteria, and

372 Deltaproteobacteria only had representative OTUs found to be inversely correlated to dissolved

373 oxygen concentrations. Representative OTUs from Alphaproteobacteria included taxa related to

374 Caulobacter and Rhodocyclaceae, both of which are bacteria that could thrive under anaerobic

375 conditions (Song et al. 2013; Oren 2014). From Deltaproteobacteria, Geobacter, a well-

376 renowned anaerobe (Lovley \& Phillips 1988; Lovley et al. 1999), was found to be negatively

377 correlated to oxygen, as was Bacteriovorax, of which much less is known regarding its

378 metabolism in freshwater systems. These results point towards taxa that may prosper in

379 developing anaerobic hypolimnetic environments after a lake mixing event has disturbed the 380 water column.

381 Frequently, OTUs were idiosyncratic in their relationships to higher or lower $\mathrm{pH}$ levels 382 within the same Phylum and ranging down to Genus (Fig. 5b). This suggests that preferences for 383 ideal environmental $\mathrm{pH}$ are often at the level of OTU, and generalizations cannot be drawn for 384 many taxonomic groups. Despite this, there were groups of bacteria that correlated 385 predominantly with decreasing $\left[\mathrm{H}^{+}\right]$, with few or no representative OTUs correlating with 386 increasing $\left[\mathrm{H}^{+}\right]$. For example, Polynucleobacter OTUs almost resoundingly correlated to 387 decreasing $\left[\mathrm{H}^{+}\right]$, despite previous research suggesting that members within this genus comprise a 
388 higher proportion of microbial communities within environments characterized by circumneutral

389 to acidic $\mathrm{pH}$ (Jezbera et al. 2012). It is possible that these taxa may have been constrained by

390 other factors (such as DOM or lack of $\mathrm{O}_{2}$ ), which limited them from thriving within lower $\mathrm{pH}$

391 environments often corresponding with lower $\mathrm{O}_{2}$ levels. From the phylum Bacteroidetes, OTUs

392 related to Chitinophagaceae, Flavobacterium, and Sphingobacteriales negatively correlated to

$393\left[\mathrm{H}^{+}\right]$, as did Proteobacteria members such as Acetobacteraceae, Hyphomonas, Methylobacter,

394 and Roseomonas. As $\mathrm{pH}$ generally decreases with increasing depth within a water column, it

395 could be superficially suggested that these taxa may be more abundant in shallower depths of the

396 water column. As an example, Bacteroidetes which negatively correlated to $\left[\mathrm{H}^{+}\right]$contained

397 OTUs which positively correlated to dissolved oxygen, suggesting that these OTUs are likely

398 present within epilimnia of stratified lakes. Interestingly, the family Acetobacteraceae, which

399 contains members of the acetic acid bacteria (including Roseomonas), are often adapted to lower

$400 \mathrm{pH}$ levels due to their ability to produce acetic acid during metabolism (Raspor \& Goranovič

401 2008). However, members within this group are obligate aerobes (Raspor \& Goranovič 2008),

402 and thus may have been unable to tolerate lower $\mathrm{O}_{2}$ conditions as may have been the case for

403 OTUs related to Polynucleobacter.

404 Temperature did not appear to have a large influence on individual microbial taxa within 405 these lakes relative to the potential influences of $\mathrm{pH}$ and dissolved oxygen (Fig. 5c). However, 406 individual OTUs spread across several phyla periodically correlated with temperature either 407 positively or negatively. Most notably, Actinomycetales, which possess thermophilic taxa (Korn408 Wendisch et al. 1995), contained three OTUs which positively correlated to temperature, 409 suggesting that these taxa may be most prevalent in shallow lakes or epilimnia. 


\section{CONCLUSION}

412 This study has found that microbial communities within actively physicochemically

413 stratifying lakes, particularly stratification of dissolved oxygen, $\mathrm{pH}$, and temperature, diverge to

414 a larger degree over time relative to communities within lakes (or points within lakes) that do not

415 chemically stratify. Additionally, despite their relatively close geographic proximity, each lake

416 harbored a distinct microbial community, suggesting that lake physicochemistry is a stronger

417 constraint on microbial communities than geographic region. Correlations of individual

418 microbial OTUs to physical and chemical variables, such as dissolved oxygen, $\mathrm{pH}$, and

419 temperature, could be related to metabolic capabilities of microbial taxonomic groups or

420 individual OTUs. This suggests that lake stratification and environmental conditions unique to

421 each lake may influence the prevalence of some microbial taxa more strongly than others,

422 thereby potentially influencing ecosystem processes carried out by these taxa. This research

423 highlights the importance of sampling lakes in the same geographic area but distinct in physical

424 and chemical attributes, as well as the potential impact of lake mixing and stratification as a

425 disturbance to microbial communities within temperate freshwater lake systems, which could

426 ultimately influence microbial community functional diversity and biogeochemical processes.

428 Acknowledgments

429 Special thanks to Stephen Lokos, Alana Miles, Greg Kinney, Dave Schuberg, and John Gordon 430 for their assistance during sampling weeks.

431

432 References 
433 Allison SD, Martiny JB (2008) Resistance, resilience, and redundancy in microbial communities.

434 Proc Natl Acad Sci 105: 11512-11519. doi:10.1073/pnas.0801925105

435

436 Amaral V, Graeber D, Calliari D, Alonso C (2016) Strong linkages between DOM optical

437 properties and main clades of aquatic bacteria. Limnol Oceanogr 61(3): 906-918.

438 doi:10.1002/lno.10258

439

440 Andrei A, Robeson MS, Baricz A, Coman C, Muntean V, Ionescu A, Etiope G, Alexe M, Sicora

441 CI, Podar M, Banciu HL (2015) Contrasting taxonomic stratification of microbial communities

442 in two hypersaline meromictic lakes. ISME J 9(12): 2642-2656. doi:10.1038/ismej.2015.60

443

444 Attermeyer K, Tittel J, Allgaier M, Frindte K, Wurzbacher C, Hilt S, Kamjunke N, Grossart H

445 (2015) Effects of Light and Autochthonous Carbon Additions on Microbial Turnover of

446 Allochthonous Organic Carbon and Community Composition. Microb Ecol 69(2): 361-371.

447 doi:10.1007/s00248-014-0549-4

448

449 Bernardet J, Segers P, Vancanneyt M, Berthe F, Kersters K, Vandamme P (1996) Cutting a

450 Gordian Knot: Emended Classification and Description of the Genus Flavobacterium, Emended

451 Description of the Family Flavobacteriaceae, and Proposal of Flavobacterium hydatis nom. nov.

452 (Basonym, Cytophaga aquatilis Strohl and Tait 1978). Int J Syst Bacteriol 46(1): 128-148.

453 doi:10.1099/00207713-46-1-128

454 
455 Bier RL, Bernhardt ES, Boot CM, Graham EB, Hall EK, Lennon JT, Nemergut DR, Osborne

456 BB, Ruiz-Gonzalez C, Schimel JP, Waldrop MP, Wallenstein MD (2015) Linking microbial

457 community structure and microbial processes: an empirical and conceptual overview. FEMS

458 Microbiol Ecol 91(10): doi:10.1093/femsec/fiv113

459

460 Boucher D, Jardillier L, Debroas D (2006) Succession of bacterial community composition over

461 two consecutive years in two aquatic systems: a natural lake and a lake-reservoir. FEMS

462 Microbiol Ecol 55(1): 79-97. doi:10.1111/j.1574-6941.2005.00011.x

463

464 Bowman JP, Nichols CM, Gibson JA (2003) Algoriphagus ratkowskyi gen. nov., sp. nov.,

465 Brumimicrobium glaciale gen. nov., sp. nov., Cryomorpha ignava gen. nov., sp. nov. and

466 Crocinitomix catalasitica gen. nov., sp. nov., novel flavobacteria isolated from various polar

467 habitats. Int J Syst Evol Microbiol 53(5): 1343-1355.

468

469 Burkert U, Warnecke F, Babenzien D, Zwirnmann E, Pernthaler J (2003) Members of a Readily

470 Enriched -Proteobacterial Clade Are Common in Surface Waters of a Humic Lake. Appl Environ

471 Microbiol 69(11): 6550-6559. doi:10.1128/aem.69.11.6550-6559.2003

472

473 Chappaz A, Curtis PJ (2013) Integrating Empirically Dissolved Organic Matter Quality for

474 WHAM VI using the DOM Optical Properties: A Case Study of $\mathrm{Cu}-\mathrm{Al}$-DOM Interactions.

475 Environ Sci Technol 47(4): 2001-2007. doi:10.1021/es3022045

476 
477 Clement TA, Murry BA, Uzarski DG (2015) Fish community size structure of small lakes: the

478 role of lake size, biodiversity and disturbance. J Freshwater Ecol 30(4): 557-568.

479

480 Cole JR, Wang Q, Fish JA, Chai B, Mcgarrell DM, Sun Y, Brown CT, Porras-Alfaro A, Kuske

481 CR, Tiedje JM (2013) Ribosomal Database Project: data and tools for high throughput rRNA

482 analysis. Nucleic Acids Res 42(D1). doi:10.1093/nar/gkt1244

483

484 Cotner JB, Biddanda BA (2002) Small Players, Large Role: Microbial Influence on

485 Biogeochemical Processes in Pelagic Aquatic Ecosystems. Ecosystems 5(2): 105-121.

486 doi:10.1007/s10021-001-0059-3

487

488 Crump BC, Kling GW, Bahr M, Hobbie JE (2003) Bacterioplankton Community Shifts in an

489 Arctic Lake Correlate with Seasonal Changes in Organic Matter Source. Appl Environ Microbiol

490

69(4): 2253-2268. doi:10.1128/aem.69.4.2253-2268.2003

491

492 Curtis PJ, Adams HE (1995) Dissolved organic matter quantity and quality from freshwater and 493 saltwater lakes in east-central Alberta. Biogeochemistry 30(1): 59-76. doi:10.1007/bf02181040 494

495 Edgar RC, Haas BJ, Clemente JC, Quince C, Knight R. (2011) UCHIME improves sensitivity 496 and speed of chimera detection. Bioinformatics 27(16): 2194-2200.

497 doi:10.1093/bioinformatics/btr381

498 
499 Eiler A, Langenheder S, Bertilsson S, Tranvik LJ (2003) Heterotrophic Bacterial Growth

500 Efficiency and Community Structure at Different Natural Organic Carbon Concentrations. Appl

501 Environ Microbiol 69(7): 3701-3709. doi:10.1128/aem.69.7.3701-3709.2003

502

503 Essington TE, Carpenter SR (2000) Mini-review: Nutrient cycling in lakes and streams: Insights 504 from a comparative analysis. Ecosystems 3(2): 131-143.

505

506 Fenchel T, Finlay B (2008) Oxygen and the Spatial Structure of Microbial Communities. Biol

507 Rev 83: 553-569. doi:10.1111/j.1469-185x.2008.00054.x

508

509 Fujimoto M, Cavaletto J, Liebig JR, McCarthy A, Vanderploeg HA, Denef, VJ (2016)

510 Spatiotemporal distribution of bacterioplankton functional groups along a freshwater estuary to

511 pelagic gradient in Lake Michigan. J Great Lakes Res 42(5): 1036-1048.

512

513 Garcia SL, Salka I, Grossart H, Warnecke F (2013) Depth-discrete profiles of bacterial

514 communities reveal pronounced spatio-temporal dynamics related to lake stratification. Environ 515 Microbiol Rep 5(4): 549-555. doi:10.1111/1758-2229.12044

516

517 Grossart H, Jezbera J, Horňák K, Hutalle KM, Buck U, Šimek K (2008) Top-down and bottom518 up induced shifts in bacterial abundance, production and community composition in an 519 experimentally divided humic lake. Environ Microbiol 10(3): 635-652. doi:10.1111/j.1462$520 \quad 2920.2007 .01487 . x$ 
522 Hahn MW (2003) Isolation of Strains Belonging to the Cosmopolitan Polynucleobacter

523 necessarius Cluster from Freshwater Habitats Located in Three Climatic Zones. Appl Environ

524 Microbiol 69(9): 5248-5254. doi:10.1128/aem.69.9.5248-5254.2003

525

526 Hahn MW, Pockl M, Wu QL (2005) Low Intraspecific Diversity in a Polynucleobacter

527 Subcluster Population Numerically Dominating Bacterioplankton of a Freshwater Pond. Appl

528 Environ Microbiol 71(8): 4539-4547. doi:10.1128/aem.71.8.4539-4547.2005

529

530 Hahn MW, Lang E, Brandt U, Lunsdorf H, Wu QL, Stackebrandt E (2010) Polynucleobacter

531 cosmopolitanus sp. nov., free-living planktonic bacteria inhabiting freshwater lakes and rivers.

532 Int J Syst Evol Microbiol 60(1): 166-173. doi:10.1099/ijs.0.010595-0

533

534 Humayoun SB, Bano N, Hollibaugh JT (2003) Depth distribution of microbial diversity in Mono

535 Lake, a meromictic soda lake in California. Appl Environ Microbiol 69(2): 1030-1042.

536

537 Jezbera J, Jezberová J, Brandt U, Hahn MW (2011) Ubiquity of Polynucleobacter necessarius 538 subspecies asymbioticus results from ecological diversification. Environ Microbiol 13(4): 922539 931. doi:10.1111/j.1462-2920.2010.02396.x

540

541 Jezbera J, Jezberová J, Koll U, Horňák K, Šimek K, Hahn MW (2012) Contrasting trends in

542 distribution of four major planktonic betaproteobacterial groups along a $\mathrm{pH}$ gradient of epilimnia 543 of 72 freshwater habitats. FEMS Microbiol Ecol 81(2): 467-479. 
545 Jones SE, Newton RJ, McMahon KD (2009). Evidence for structuring of bacterial community

546 composition by organic carbon source in temperate lakes. Environ Microbiol 11(9): 2463-2472.

547

548 Kim C, Nishimura Y, Nagata T (2006) Role of dissolved organic matter in hypolimnetic

549 mineralization of carbon and nitrogen in a large, monomictic lake. Limnol Oceanogr 51(1): 70-

550 78. doi: $10.4319 / 10.2006 .51 .1 .0070$

551

552 Korn-Wendisch F, Rainey F, Kroppenstedt RM, Kempf A, Majazza A, Kutzner HJ, Stackebrandt

553 E (1995) Thermocrispum gen. nov., a New Genus of the Order Actinomycetales, and Description 554 of Thermocrispum municipale sp. nov. and Thermocrispum agreste sp. nov. Int J Syst Evol

555 Microbiol 45(1): 67-77.

556

557 Kozich JJ, Westcott SL, Baxter NT, Highlander SK, Schloss PD (2013) Development of a Dual-

558 Index Sequencing Strategy and Curation Pipeline for Analyzing Amplicon Sequence Data on the

559 MiSeq Illumina Sequencing Platform. Appl Environ Microbiol 79(17): 5112-5120.

560 doi:10.1128/aem.01043-13

561

562 Li W, Wu F, Liu C, Fu P, Wang J, Mei Y, Wang LY, Guo JY (2008) Temporal and spatial

563 distributions of dissolved organic carbon and nitrogen in two small lakes on the Southwestern

564 China Plateau. Limnology 9(2): 163-171. doi:10.1007/s10201-008-0241-9

565

566 Liu Y, Li H, Jiang JT, Liu YH, Song XF, Xu CJ, Liu ZP (2009) Algoriphagus aquatilis sp. nov., 567 isolated from a freshwater lake. Int J Syst Evol Microbiol 59(7): 1759-1763. 
568

569 Love MI, Huber W, Anders S (2014) Moderated estimation of fold change and dispersion for 570 RNA-Seq data with DESeq2. Genome Biol 15(12): 550.

571

572 Lovley DR, Phillips EJ (1988) Novel mode of microbial energy metabolism: organic carbon 573 oxidation coupled to dissimilatory reduction of iron or manganese. Appl Environ Microbiol 54: $574 \quad 1472-1480$.

575

576 Lovley DR, Fraga JL, Coates JD, Blunt-Harris EL (1999) Humics as an electron donor for 577 anaerobic respiration. Environ Microbiol 1(1): 89-98. doi:10.1046/j.1462-2920.1999.00009.x

578

579 Lucas J, Koester I, Wichels A, Niggemann J, Dittmar T, Callies U, Wiltshire KH, Gerdts G 580 (2016) Short-Term Dynamics of North Sea Bacterioplankton-Dissolved Organic Matter 581 Coherence on Molecular Level. Front Microbiol 7. doi:10.3389/fmicb.2016.00321

582

583 Mcknight DM, Boyer EW, Westerhoff PK, Doran PT, Kulbe T, Andersen DT (2001)

584 Spectrofluorometric characterization of dissolved organic matter for indication of precursor 585 organic material and aromaticity. Limnol Oceanogr 46(1): 38-48. doi:10.4319/1o.2001.46.1.0038 586

587 McMurdie PJ, Holmes S (2013) Phyloseq: an R package for reproducible interactive analysis and 588 graphics of microbiome census data. PLOS ONE 8(4). 
590 McMurdie PJ, Holmes S (2014). Waste not, want not: why rarefying microbiome data is

591 inadmissible. PLoS Comput Biol, 10(4). e1003531.

592

593 Meuser JE, Baxter BK, Spear JR, Peters JW, Posewitz MC, Boyd ES (2013) Contrasting Patterns 594 of Community Assembly in the Stratified Water Column of Great Salt Lake, Utah. Microb Ecol 595 66(2): 268-280. doi:10.1007/s00248-013-0180-9

596

597 Meyer F, Paarmann D, D'souza M, Olson R, Glass E, Kubal M, Paczian T, Rodriguez A, Stevens

598 R, Wilke A, Wilkening J, Edwards R (2008) The metagenomics RAST server - a public resource 599 for the automatic phylogenetic and functional analysis of metagenomes. BMC Bioinformatics 600 9(1): 386. doi:10.1186/1471-2105-9-386

601

602 Meyerhof MS, Wilson JM, Dawson MN, Michael Beman J (2016) Microbial community 603 diversity, structure and assembly across oxygen gradients in meromictic marine lakes, Palau. 604 Environ Microbiol 18(12): 4907-4919.

605

606 Mostofa KM, Yoshioka T, Konohira E, Tanoue E, Hayakawa K, Takahashi M (2005) Three607 dimensional fluorescence as a tool for investigating the dynamics of dissolved organic matter in 608 the Lake Biwa watershed. Limnology 6(2): 101-115. doi:10.1007/s10201-005-0149-6 609

610 Mou X, Jacob J, Lu X, Robbins S, Sun S, Ortiz JD (2013) Diversity and distribution of free-

611 living and particle-associated bacterioplankton in Sandusky Bay and adjacent waters of Lake 612 Erie Western Basin. J Gt Lakes Res 39(2): 352-357. doi:10.1016/j.jglr.2013.03.014 
613

614 Okazaki Y, Fujinaga S, Tanaka A, Kohzu A, Oyagi H, Nakano SI (2016) Ubiquity and

615 quantitative significance of bacterioplankton lineages inhabiting the oxygenated hypolimnion of

616 deep freshwater lakes. ISME J. doi:10.1038/ismej.2017.89

617

618 Oksanen J, Blanchet FG, Friendly M, Kindt R, Legendre P, McGlinn D, Minchin R, O’Hara RB,

619 Simpson GL, Solymos P, Stevens MHH, Szoecs Ed, Wagner H (2017) Vegan: community

620 ecology package. R package version 2.4-2. http://CRAN.R-project.org/package=vegan.

621

622 Oren A (2014) The family rhodocyclaceae. In: The Prokaryotes. Springer Berlin Heidelberg.

623

624 Paerl HW, \& Pinckney JL (1996) A mini-review of microbial consortia: their roles in aquatic 625 production and biogeochemical cycling. Microb Ecol 31(3): 225-247.

626

627 Pilcher DJ, McKinley GA, Bootsma HA, Bennington V (2015) Physical and biogeochemical

628 mechanisms of internal carbon cycling in Lake Michigan. Geophys Res, C, Oceans 120(3):

$629 \quad 2112-2128$.

630

631 Quast C, Pruesse E, Yilmaz P, Gerken J, Schweer T, Yarza P, Peplies J, Glöckner FO (2012).

632 The SILVA ribosomal RNA gene database project: improved data processing and web-based 633 tools. Nucleic Acids Res, 41(D1): D590-D596.

634 
635 R Core Team (2015) R: A language and environment for statistical computing. Vienna, Austria.

636 https://www.R-project.org/.

637

638 Ramana CV, Sasikala C (2009) Albidoferax, a new genus of Comamonadaceae and

639 reclassification of Rhodoferax ferrireducens (Finneran et al., 2003) as Albidoferax ferrireducens

640 comb. nov. J Gen Appl Microbiol 55(4): 301-304.

641

642 Raspor P, Goranovič D (2008) Biotechnological applications of acetic acid bacteria. Crit Rev

643 Biotechnol 28(2): 101-124.

644

645 Rosenberg E (2014) The family Chitinophagaceae. In: The Prokaryotes. Springer Berlin

646 Heidelberg.

647

648 Schloss PD, Westcott SL, Ryabin T, Hall JR, Hartmann M, Hollister EB, Lesniewski RA,

649 Oakley BB, Parks DH, Robinson CJ, Sahl JW, Stres B, Thallinger GG, Van Horn DJ, Weber CF

650 (2009) Introducing mothur: Open-Source, Platform-Independent, Community-Supported

651 Software for Describing and Comparing Microbial Communities. Appl Environ Microbiol

652 75(23): 7537-7541. doi:10.1128/aem.01541-09

653

654 Shade A, Jones SE, Mcmahon KD (2008) The influence of habitat heterogeneity on freshwater

655 bacterial community composition and dynamics. Environ Microbiol 10(4): 1057-1067.

656 doi:10.1111/j.1462-2920.2007.01527.x

657 
658 Shade A, Chiu C, Mcmahon KD (2010a) Seasonal and Episodic Lake Mixing Stimulate

659 Differential Planktonic Bacterial Dynamics. Microb Ecol 59(3): 546-554. doi:10.1007/s00248-

$660 \quad 009-9589-6$

661

662 Shade A, Chiu C, Mcmahon KD (2010b) Differential bacterial dynamics promote emergent

663 community robustness to lake mixing: an epilimnion to hypolimnion transplant experiment.

664 Environ Microbiol 12(2): 455-466. doi:10.1111/j.1462-2920.2009.02087.x

665

666 Shade A, Read JS, Welkie DG, Kratz TK, Wu CH, Mcmahon KD (2011) Resistance, resilience

667 and recovery: aquatic bacterial dynamics after water column disturbance. Environ Microbiol

668 13(10): 2752-2767. doi:10.1111/j.1462-2920.2011.02546.x

669

670 Shade A, Peter H, Allison SD, Baho DL, Berga M, Bürgmann H, Huber DH, Langengeder S,

671 Lennon JT, Martiny JBH, Matulich KL, Schmidt TM, Handelsman J (2012a) Fundamentals of

672 Microbial Community Resistance and Resilience. Front Microbiol 3: 1-19.

673 doi:10.3389/fmicb.2012.00417

674

675 Shade A, Read JS, Youngblut ND, Fierer N, Knight R, Kratz TK, Lottig NR, Roden EE, Stanley

676 EH, Stombaugh J, Whitaker RJ, Wu CH, McMahon KD (2012b) Lake microbial communities

677 are resilient after a whole-ecosystem disturbance. ISME J 6(12): 2153-2167.

678 doi:10.1038/ismej.2012.56

679 
680 Song N, Cai HY, Yan ZS, Jiang HL (2013) Cellulose degradation by one mesophilic strain

681 Caulobacter sp. FMC1 under both aerobic and anaerobic conditions. Bioresour Technol 131:

$682 \quad 281-287$.

683

684 Taipale S, Jones R, Tiirola M (2009) Vertical diversity of bacteria in an oxygen-stratified humic 685 lake, evaluated using DNA and phospholipid analyses. Aquat Microb Ecol 55: 1-16.

686 doi:10.3354/ame01277

687

688 Tammert H, Kisand V, Nõges T (2005) Bacterioplankton abundance and activity in a small 689 hypertrophic stratified lake. Hydrobiologia 547: 83-90. doi:10.1007/1-4020-4363-5_8

690

691 Tõnno I, Ott K, Nõges T (2005) Nitrogen dynamics in the steeply stratified, temperate Lake 692 Verevi, Estonia. Hydrobiologia 547: 63-71. doi:10.1007/1-4020-4363-5_6

693

694 Van der Gucht K, Cottenie K, Muylaert K, Vloemans N, Cousin S, Declerck S, Jeppesen E, 695 Conde-Porcuna J, Schwenk K, Zwart G, Degans H, Vyverman W, De Meester L (2007) The 696 power of species sorting: local factors drive bacterial community composition over a wide range 697 of spatial scales. Proc Natl Acad Sci 104(51): 20404-20409.

698

699 Weisburg WG, Barns SM, Pelletier DA, Lane DJ (1991) 16S ribosomal DNA amplification for 700 phylogenetic study. J Bacteriol 173(2): 697-703. doi:10.1128/jb.173.2.697-703.1991 
702 Weishaar JL, Aiken GR, Bergamaschi BA, Fram MS, Fujii R, Mopper K (2003) Evaluation of

703 Specific Ultraviolet Absorbance as an Indicator of the Chemical Composition and Reactivity of

704 Dissolved Organic Carbon. Environ Sci Technol 37(20): 4702-4708. doi:10.1021/es030360x

705

706 Wetzel RG (2001) Limnology: lake and river ecosystems. Gulf Professional Publishing.

707

708 Yannarell A C, Triplett EW (2005) Geographic and environmental sources of variation in lake

709 bacterial community composition. Appl Environ Microbiol 71(1): 227-239.

710

711 Zadereev E, Tolomeev A, Drobotov A (2014) Spatial and Seasonal Dynamics of Dissolved and

712 Suspended Nutrients in the Water Column of Meromictic Lake Shira. Acta Geol Sin 88: 173-

713 174. doi:10.1111/1755-6724.12267_18

714

715 Zwart G, Crump B, Agterveld MK, Hagen F, Han S (2002) Typical freshwater bacteria: an

716 analysis of available 16S rRNA gene sequences from plankton of lakes and rivers. Aquat Microb

717 Ecol 28: 141-155. doi:10.3354/ame028141

718

719 


\section{Figure Captions}

721 Figure 1. Map of sampled lakes in the Beaver Island region. Shapes correspond to lake sampled.

722

723 Figure 2. Principal Component Analysis (PCA) demonstrating separation of all sampling points

724 based on measured environmental variables $(\mathrm{pH}$, temperature, nitrate, ammonium, nitrate,

725 dissolved oxygen, and dissolved organic carbon). Circles = Barney's Lake, squares = Fox Lake,

726 diamonds = Lake Geneserath, triangles = Lake Michigan. Open shapes correspond to surface-

727 water samples, while filled shapes correspond to bottom-water samples. Numbers associated

728 with points correspond to time point of sampling (higher numbers are later in the summer). DO=

729 dissolved oxygen; DOC = dissolved organic carbon; NH4 = ammonium; NO3 = nitrate; Temp =

730 temperature. SAC340 and $\mathrm{NO}_{3}^{-}$data were highly correlated (Spearman Rank, r $=0.82, \mathrm{p}<$

731 0.001) so both were represented by " $\mathrm{NO}_{3}$ " in the PCA

732

733 Figure 3. Taxonomic composition and relative abundance ( $>1 \%$ relative abundance) of

734 community members broken down by phylum at each sampling location. Labeling scheme is

735 represented by lake (eg., LG, FL, BL, and LM), followed by habitat (eg., surface-water [S] and

736 bottom-water [B]), and finally sampling time point (eg., P1 = sampling time 1, P2 = sampling

737 time 2, etc.).

738

739 Figure 4. Non-metric Multidimensional Scaling (NMDS) of microbial communities within each

740 sampled lake. Circles = Barney's Lake, squares = Fox Lake, diamonds = Lake Geneserath,

741 triangles = Lake Michigan. Open shapes correspond to surface-water samples, while filled

742 shapes correspond to bottom-water samples. Numbers associated with points correspond to time 
743 point of sampling. Vectors correspond to environmental variables significantly correlated (p <

$7440.001, \mathrm{R}>0.5$ ) to separation of microbial communities within NMDS. DO = dissolved oxygen;

745 DOC $=$ dissolved organic carbon; Temp $=$ temperature.

746

747 Figure 5. Bar plot illustrating correlations of taxonomic groups (identified to their lowest

748 phylogenetic classification) to environmental variables a. dissolved oxygen (DO), b. $\mathrm{pH}([\mathrm{H}+])$,

749 and c. temperature (Temp). Abundance values indicate number of OTUs identified to a 750 taxonomic group either positively or negatively correlated to an environmental variable. Values

751 above the "0" line indicate positively correlated OTU abundances, while values below this same

752 line represent negatively correlated OTU abundances. Bar colors correspond to the phylum each

753 lower taxonomic group belongs to.

754

755 Supplemental Figure 1. Canonical Correspondence Analysis (CCA) of microbial communities

756 across lakes. Circles = Barney’s Lake, squares $=$ Fox Lake, diamonds $=$ Lake Geneserath, 757 triangles = Lake Michigan. Open shapes correspond to surface-water samples, while filled 758 shapes correspond to bottom-water samples. Numbers associated with points correspond to time 759 point of sampling. Vectors correspond to environmental variables used to constrain variability in 760 CCA. $\mathrm{DO}=$ dissolved oxygen; $\mathrm{DOC}=$ dissolved organic carbon; Temp $=$ temperature. 761 Percentages associated with axes correspond to percent constrained variability explained.

763 Supplemental Figure 2. Partial Canonical Correspondence Analysis (pCCA) of microbial 764 communities across lakes with oxygen as the constraining variable while controlling for 765 variability caused by temperature and $\mathrm{pH}$. Circles $=$ Barney's Lake, squares $=$ Fox Lake, 
766 diamonds = Lake Geneserath, triangles = Lake Michigan. Open shapes correspond to surface767 water samples, while filled shapes correspond to bottom-water samples. Numbers associated 768 with points correspond to time point of sampling. Vectors correspond to environmental variables 769 used to constrain variability in CCA. DO = dissolved oxygen. Percentages associated with axes 770 correspond to percent total variability explained. 


\section{Figure 1 (on next page)}

\section{Map of sampling region}

Map of sampled lakes in the Beaver Island region. Shapes correspond to lake sampled. 


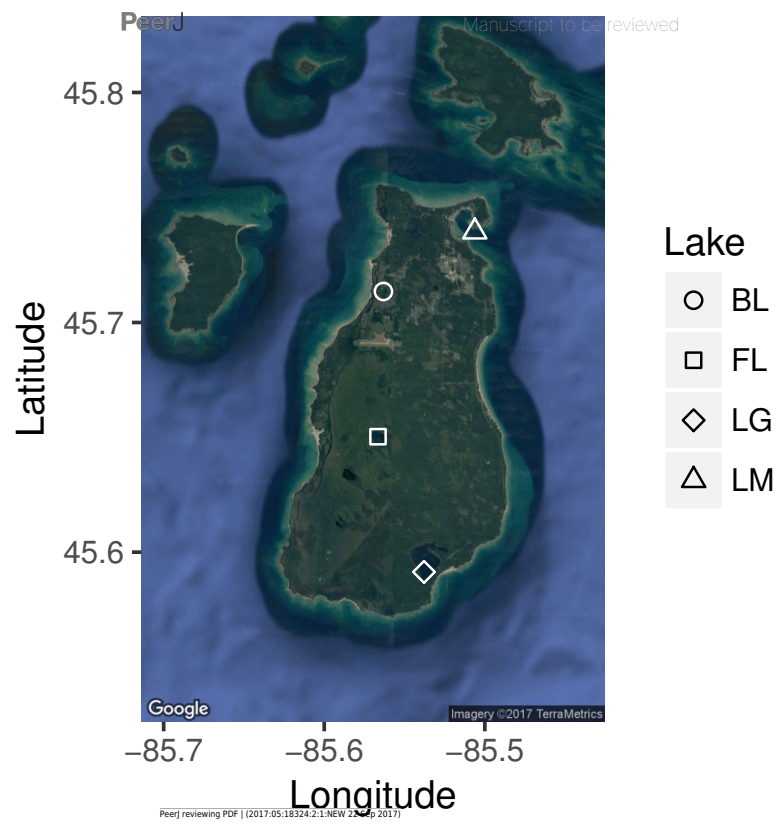




\section{Figure 2 (on next page)}

Principal Component Analysis (PCA) demonstrating separation of all sampling points based on measured environmental variables

Principal Component Analysis (PCA) demonstrating separation of all sampling points based on measured environmental variables ( $\mathrm{pH}$, temperature, nitrate, ammonium, nitrate, dissolved oxygen, and dissolved organic carbon). Circles = Barney's Lake, squares $=$ Fox Lake, diamonds $=$ Lake Geneserath, triangles $=$ Lake Michigan. Open shapes correspond to surface-water samples, while filled shapes correspond to bottom-water samples. Numbers associated with points correspond to time point of sampling (higher numbers are later in the summer). $\mathrm{DO}=$ dissolved oxygen; $\mathrm{DOC}=$ dissolved organic carbon; $\mathrm{NH} 4=$ ammonium; $\mathrm{NO3}$ $=$ nitrate; Temp $=$ temperature. $\mathrm{SAC}_{40}$ and $\mathrm{NO}_{3}{ }^{-}$data were highly correlated (Spearman Rank, $r=0.82, p<0.001$ ) so both were represented by " $\mathrm{NO}_{3}$ " in the PCA. 


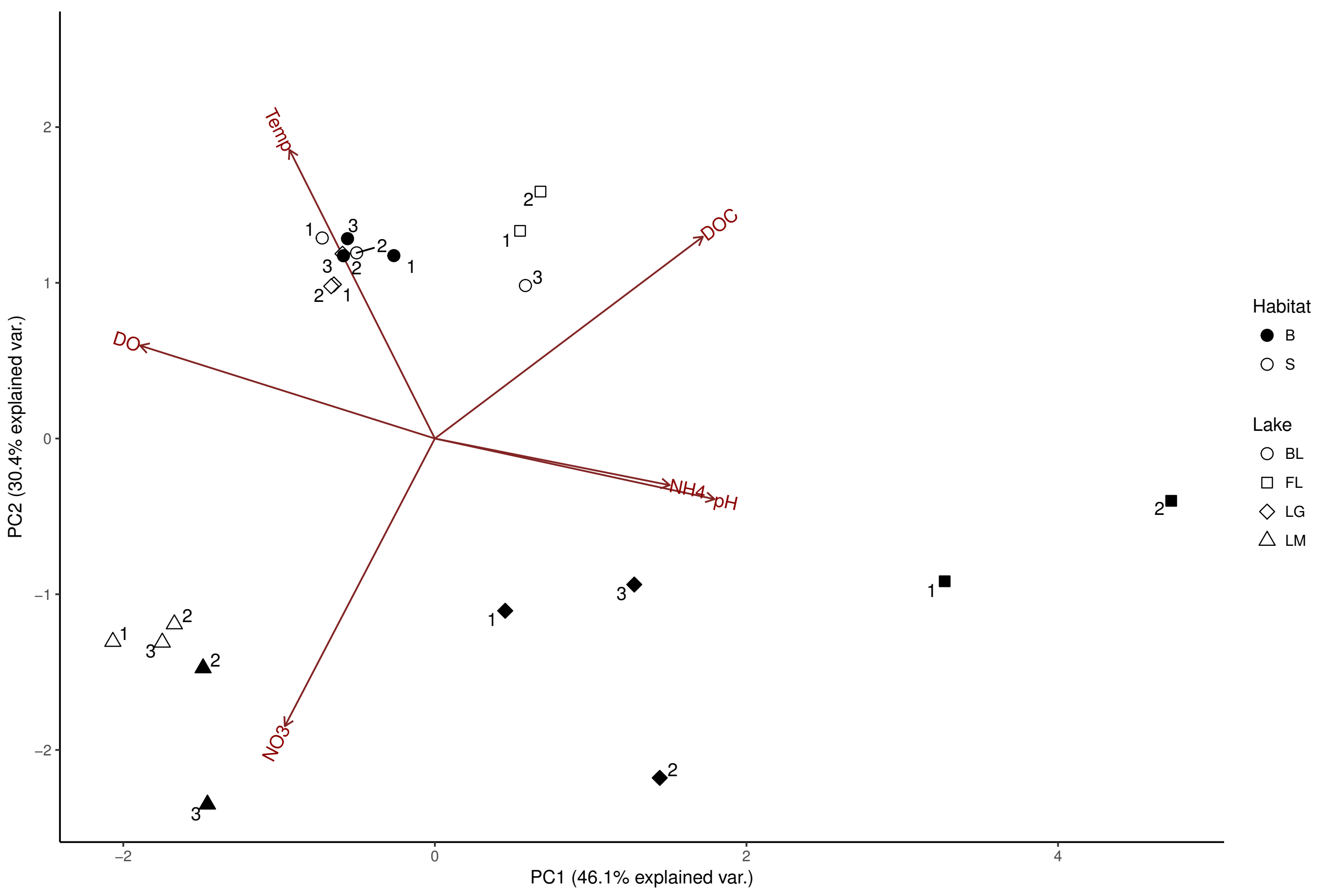




\section{Figure 3 (on next page)}

Taxonomic composition

Taxonomic composition and relative abundance ( $>1 \%$ relative abundance) of community members broken down by phylum at each sampling location. Labeling scheme is represented by lake (eg., LG, FL, BL, and LM), followed by habitat (eg., surface-water [S] and bottomwater $[B]$ ), and finally sampling time point (eg., P1 = sampling time 1, P2 = sampling time 2 , etc.). 


\section{Figure 4 (on next page)}

Non-metric Multidimensional Scaling (NMDS) of microbial communities

NMDS of microbial communities within each sampled lake. Circles = Barney's Lake, squares $=$ Fox Lake, diamonds $=$ Lake Geneserath, triangles $=$ Lake Michigan. Open shapes correspond to surface-water samples, while filled shapes correspond to bottom-water samples. Numbers associated with points correspond to time point of sampling. Vectors correspond to environmental variables significantly correlated $(p<0.001, R>0.5)$ to separation of microbial communities within NMDS. DO = dissolved oxygen; $D O C=$ dissolved organic carbon; Temp = temperature. 


\section{Figure 5 (on next page)}

Bar plot of taxonomic groups

Bar plot illustrating correlations of taxonomic groups (identified to their lowest phylogenetic classification) to environmental variables a. dissolved oxygen (DO), b. $\mathrm{pH}([\mathrm{H}+])$, and c. temperature (Temp). Abundance values indicate number of OTUs identified to a taxonomic group either positively or negatively correlated to an environmental variable. Values above the " 0 " line indicate positively correlated OTU abundances, while values below this same line represent negatively correlated OTU abundances. Bar colors correspond to the phylum each lower taxonomic group belongs to. 


\section{Table $\mathbf{1}$ (on next page)}

Limnological characteristic

Limnological characteristic ranges for the surface and bottom water of each lake during the duration of this study. Temp $=$ temperature, $\mathrm{DO}=$ dissolved oxygen, $\mathrm{DOC}=$ dissolved organic carbon. 
1 Table 1. Limnological characteristic ranges for the surface and bottom water of each lake during

2 the duration of this study. Temp $=$ temperature, $\mathrm{DO}=$ dissolved oxygen, $\mathrm{DOC}=$ dissolved

3 organic carbon.

\begin{tabular}{|c|c|c|c|c|c|}
\hline & Habitat & Temp $\left({ }^{\circ} \mathrm{C}\right)$ & $\mathrm{pH}$ & DO $(\%)$ & $\begin{array}{l}\text { DOC } \\
(\mathrm{mg} / \mathrm{L})\end{array}$ \\
\hline Barney's Lake & $\begin{array}{l}\text { Surface } \\
\text { Bottom }\end{array}$ & $\begin{array}{l}20.7-21.7 \\
20.4-21.2\end{array}$ & $\begin{array}{l}8.57- \\
8.75 \\
8.52- \\
8.75\end{array}$ & $\begin{array}{l}103.1- \\
118.7 \\
103.7- \\
113.9\end{array}$ & $\begin{array}{l}10.7-11.4 \\
10.6-11.2\end{array}$ \\
\hline Fox Lake & $\begin{array}{l}\text { Surface } \\
\text { Bottom }\end{array}$ & $\begin{array}{l}20.7-21.5 \\
11.1-12.5\end{array}$ & $\begin{array}{l}6.13- \\
6.53 \\
5.46- \\
5.79\end{array}$ & $\begin{array}{l}90.7-93.8 \\
0-25.4\end{array}$ & $\begin{array}{l}16.0-17.6 \\
16.2-18.5\end{array}$ \\
\hline $\begin{array}{l}\text { Lake } \\
\text { Geneserath }\end{array}$ & $\begin{array}{l}\text { Surface } \\
\text { Bottom }\end{array}$ & $\begin{array}{l}19.7-21.4 \\
8.8-9.1\end{array}$ & $\begin{array}{l}8.05- \\
8.29 \\
6.49- \\
6.78\end{array}$ & $\begin{array}{l}97.8- \\
103.4 \\
0-64.0\end{array}$ & $\begin{array}{l}9.2-9.8 \\
9.0-9.2\end{array}$ \\
\hline Lake Michigan & $\begin{array}{l}\text { Surface } \\
\text { Bottom }\end{array}$ & $\begin{array}{l}16.1-18.2 \\
8.1-15.9\end{array}$ & $\begin{array}{l}8.12- \\
8.28 \\
7.84- \\
8.08\end{array}$ & $\begin{array}{l}102.1- \\
124.5 \\
103.4-120\end{array}$ & $\begin{array}{l}2.4-2.8 \\
2.1-2.6\end{array}$ \\
\hline
\end{tabular}


Table 2 (on next page)

Alpha Diversity

Shannon diversity values for microbial communities from each collection point. 
1 Table 2. Shannon diversity values for microbial communities from each collection point.

\begin{tabular}{lccc} 
Lake & Habitat & Time & Shannon \\
\hline BL & B & 1 & 4.21 \\
& & 2 & 4.83 \\
& & 3 & 4.32 \\
& S & 1 & 3.59 \\
& & 2 & 4.07 \\
& & 3 & 4.27 \\
\hline FL & B & 1 & 4.19 \\
& & 2 & 4.91 \\
& S & 1 & 3.22 \\
& & 2 & 4.72 \\
\hline LG & B & 1 & 4.01 \\
& & 2 & 4.33 \\
& & 3 & 4.67 \\
& S & 1 & 3.73 \\
& & 2 & 4.7 \\
& & 3 & 4.29 \\
\hline LM & B & 2 & 4.49 \\
& & 3 & 4.91 \\
& S & 1 & 3.48 \\
& & 2 & 3.74 \\
& & 3 & 3.18 \\
\hline
\end{tabular}

2 